$9-1-2003$

\title{
Rare complication of sinus venosus-type atrial septal defect repair
}

M Murad

S A. Sami

Aga Khan University, shahid.sami@aku.edu

R Hashmi

V Bari

Aga Khan University, vaqar.bari@aku.edu

Follow this and additional works at: https://ecommons.aku.edu/pakistan_fhs_mc_radiol

Part of the Radiology Commons

\section{Recommended Citation}

Murad, M., Sami, S. A., Hashmi, R., Bari, V. (2003). Rare complication of sinus venosus-type atrial septal defect repair. European Journal of Nuclear Medicine and Molecular Imaging, 30(9), 1315.

Available at: https://ecommons.aku.edu/pakistan_fhs_mc_radiol/249 


\title{
Rare complication of sinus venosus-type atrial septal defect repair
}

\author{
M. Murad ${ }^{1}$, S. A. Sami², R. Hashmi ${ }^{1}$, V. Bari ${ }^{1}$ \\ 1 Section of Nuclear Medicine, Department of Radiology, Aga Khan University Hospital, Karachi, Pakistan \\ 2 Cardio-thoracic Surgery Section, Department of Surgery, Aga Khan University Hospital, Karachi, Pakistan
}

Published online: 29 July 2003

(C) Springer-Verlag 2003

Eur J Nucl Med Mol Imaging (2003) 30:1315

DOI 10.1007/s00259-003-1272-4

Pulmonary embolism was considered after sinus venosus defect repair. Upper arm injection for lung perfusion study demonstrated uptake in the brain, kidney, myocardium and spleen but not in the lungs (complete right to left shunt).

A rare complication of corrective surgery for sinus venosus defect is diversion of the superior vena cava (SVC) to the left atrium, draining SVC blood to systemic circulation.

M. Murad ( $\bullet$ )

Section of Nuclear Medicine, Department of Radiology,

Aga Khan University Hospital, Stadium Road, P.O. Box 3500,

74800 Karachi, Pakistan

e-mail: moazzammurad@hotmail.com

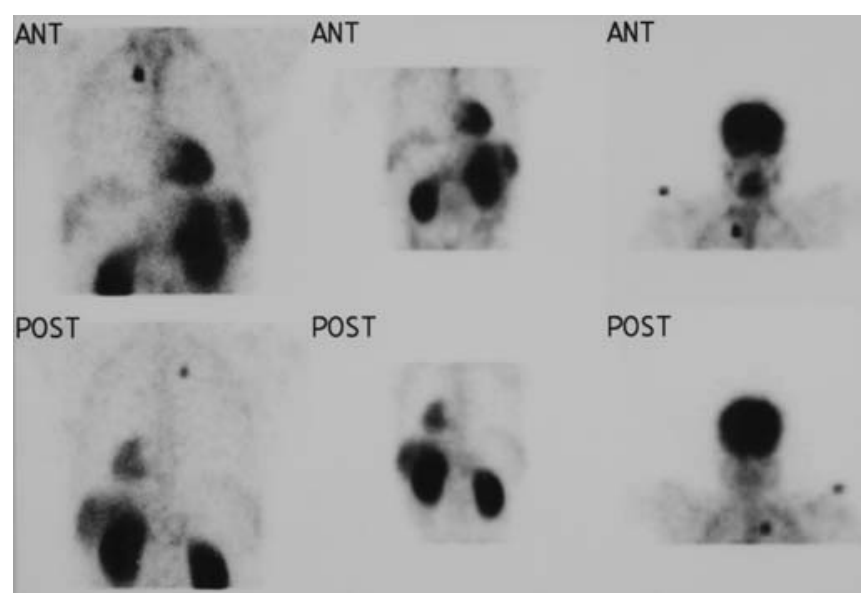

